\title{
Nanocrystalline Al Composites from Powder Milled under Ammonia Gas Flow
}

\author{
J. Cintas, ${ }^{1}$ E. S. Caballero, ${ }^{1}$ J. M. Montes, ${ }^{1}$ F. G. Cuevas, ${ }^{2}$ and C. Arevalo ${ }^{1}$ \\ ${ }^{1}$ Metallurgy and Materials Engineering Group, Escuela Técnica Superior de Ingeniería, University of Seville, \\ Camino de los Descubrimientos $s / n, 41092$ Sevilla, Spain \\ ${ }^{2}$ Department of Chemistry and Materials Science, Escuela Técnica Superior de Ingeniería, University of Huelva, \\ Campus La Rábida, Carretera Palos s/n, Palos de la Frontera, 21819 Huelva, Spain
}

Correspondence should be addressed to J. Cintas; jcintas@us.es

Received 22 October 2013; Revised 14 January 2014; Accepted 15 January 2014; Published 27 February 2014

Academic Editor: Denis Chaumont

Copyright (C) 2014 J. Cintas et al. This is an open access article distributed under the Creative Commons Attribution License, which permits unrestricted use, distribution, and reproduction in any medium, provided the original work is properly cited.

\begin{abstract}
The production of high hardness and thermally stable nanocrystalline aluminium composites is described. Al powder was milled at room temperature in an ammonia flow for a period of less than $5 \mathrm{~h} . \mathrm{NH}_{3}$ dissociation during milling provokes the absorption, at a high rate, of nitrogen into aluminium, hardening it by forming a solid solution. Controlled amounts of $\mathrm{AlN}^{\mathrm{N}}$ and $\mathrm{Al}_{5} \mathrm{O}_{6} \mathrm{~N}$ are formed during the subsequent sintering of milled powders for consolidation. The pinning action of these abundant dispersoids highly restrains aluminium grain growth during heating. The mean size of the $\mathrm{Al}$ grains remains below $45 \mathrm{~nm}$ and even after the milled powder is sintered at $650^{\circ} \mathrm{C}$ for $1 \mathrm{~h}$.
\end{abstract}

\section{Introduction}

Nanostructured materials are promising materials that offer new opportunities for substantially improving the standard of living. Over the last years, nanostructured materials research has grown significantly [1-3]. Grain size reduction to the nanometre scale allows for improvements in mechanical properties, as has been shown by several researchers [4-8]. Currently, the most common processing methods for the production of nanocrystalline materials include inert gas condensation, chemical reaction methods, electrodeposition, severe plastic deformation, and mechanical milling $[9,10]$. The latter, also called high-energy milling or mechanical alloying, is considered one of the main techniques in this regard $[11,12]$.

$\mathrm{Al}$ powder has traditionally been reinforced with a variety of micron-size directly added ceramic particles, such as alumina, silicon carbide, titanium carbide, and others [1315]. Recently, Al-matrix composites reinforced with submicrometric $(0.1-1 \mu \mathrm{m})$ and nanometric $(<0.1 \mu \mathrm{m})$ particles have been widely studied $[16,17]$. However, one of the main challenges towards achieving a homogeneous distribution of a nanometric ceramic phase in a metal matrix is avoiding agglomeration of the reinforcement particles [18].

It has been found that the reinforcement of aluminium powders is more homogeneous when these dispersoids are formed through direct reaction of the aluminium with its environment, rather than by simply mixing aluminium with ceramic composites [19-22]. Aluminium easily reacts with elements such as $\mathrm{C}, \mathrm{O}, \mathrm{N}$, and $\mathrm{H}$, which leads to difficulties in its traditional processing, but this reactivity can be positively used through mechanical alloying to form, after thermal treatments, several phases finely dispersed in the matrix. These phases, such as aluminium oxide $\left(\mathrm{Al}_{2} \mathrm{O}_{3}\right)$, carbide $\left(\mathrm{Al}_{4} \mathrm{C}_{3}\right)$, nitride $(\mathrm{AlN})$, oxynitrides, and oxycarbonitrides [19], perform as reinforcing instead of embrittling agents. In the presence of hydrogen, aluminium forms hydrides, which are brittle, but they are easily removed by heating, forming hydrogen, which is evacuated during sintering $[23,24]$.

On the other hand, aluminium nitride possesses excellent conductivity, low thermal expansion, high hardness, and good oxidation resistance at elevated temperatures [25]. These characteristics suggest that AlN may be an acceptable reinforcement not only for mechanical applications but also 
for physical aims such as electronic applications, when the composite/substrate junction must have no significant distortions with thermal changes [26]. Several preparation methods of $\mathrm{Al} / \mathrm{AlN}$ composite materials have been reported. Most of them are based on pressure or pressureless metal infiltration, spray deposition and hot pressing, squeeze casting, and mechanical alloying [27-31].

This paper describes a new and simple method to obtain aluminium-based nanostructured components reinforced by self-forming nanometric AlN. These reinforcements are formed through the mechanosynthesis of $\mathrm{Al}$ powders in an ammonia gas flow at room temperature for relatively short milling times $(5 \mathrm{~h})$, followed by a conventional powder metallurgy consolidation process.

\section{Materials and Methods}

The starting material was atomised elemental aluminium powder (ECKA AS 61, Eckart-Werke, Germany), with a purity higher than $99.7 \%$ and a mean particle size of $80.5 \mu \mathrm{m}$. Aluminium powder was milled in a high-energy attritor ballmill (Union Process, USA). The water-cooled stainless steel vessel used has a $1400 \mathrm{~cm}^{3}$ capacity. A $3 \mathrm{wt} . \%$ micropowder organic wax (etilen bis-stearamide) was used to control the welding and fracture processes of $\mathrm{Al}$ powder during milling. The mill charge contained $72 \mathrm{~g}$ of powder and $3600 \mathrm{~g}$ of balls (charge ratio in wt.\%: $50: 1$ ). The milling processes were performed in an ammonia $\left(\mathrm{NH}_{3}\right)$ flow of $1 \mathrm{~cm}^{3} / \mathrm{s}$ with a purity higher than $99.96 \%$.

In order to study the evolution of the morphology and microstructure of the powders, milling was performed from 1 to $5 \mathrm{~h}$ with rotor speeds of 300 and $500 \mathrm{rpm}$. For comparison, a milling process in vacuum (5 Pa) at $500 \mathrm{rpm}$ for $5 \mathrm{~h}$ was also performed. The powder particle sizes were measured by laser diffraction (Malvern, Mastersizer 2000), whereas the morphology was studied by a scanning electron microscope (SEM, Philips XL-30) equipped with an energy dispersive microanalysis system. To measure the powder compressibility, a universal testing machine (Instron, 5505) with a load cell of $100 \mathrm{kN}$ was used.

The milled powders were consolidated by cold uniaxial pressing $(1300 \mathrm{MPa})$ and vacuum $(5 \mathrm{~Pa})$ sintering $\left(650^{\circ} \mathrm{C}\right.$ for $1 \mathrm{~h}$ ). X-ray diffraction measurements (XRD, Bruker D8 Advance, using $\mathrm{CuK} \alpha$ radiation) and transmission electron microscopy (TEM, Phillips CM 200) of milled and sintered powders were used to identify, quantify, and measure the crystallite and grain size of the phases formed. Vickers hardness (Struers Duramin A300) of sintered compacts was evaluated using a load of $1 \mathrm{~kg}$, whereas relative density was determined both by Archimedes' principle and by mass and dimensions measurement.

\section{Results and Discussion}

3.1. Granulometry. Figure 1 displays the granulometric distribution of the as-received aluminium ( $\mathrm{ARAl}$ ) and the mechanically alloyed powders, at 300 and $500 \mathrm{rpm}$, in an ammonia gas flow (MA A 300 and MA A 500, resp.).
The curve of the MA A 500 powders (Figure 1(b)) shows that, contrary to that expected for a ductile powder such as aluminium, the particle size decreases from its initial value (powder milled for $1 \mathrm{~h}$, MA A 500-1). This is due to the rapid dissociation and adsorption of components of the ammonia from the beginning of the mechanical alloying process, strengthening the aluminium by solid solution. This strengthening associated with high-energy milling is responsible for the rapid particle size decrease. On the other hand, lack of symmetry is observed in the curves of the 3and 5-h milled powders (MA A 500-3 and MA A 500-5). This could be related to the small particle size of these powders, which significantly promotes powder agglomeration.

In contrast, the lower energy of the process when milling at $300 \mathrm{rpm}$ causes a slower particle size evolution (Figure 1(a)). The powder requires more time to harden, homogenise. and decrease in size. Therefore, the MA A 300 powders have a larger mean particle size (Figure 1(c)) and a broader particle size distribution as compared to the MA A 500 powders for the same milling time. Furthermore, the lower milling energy and the consequent increase of the particle welding processes are also responsible for the higher particle size observed after $1 \mathrm{~h}$ (MA A 300-1) as compared with the AR Al (Figure 1(c)).

3.2. Morphology. Figure 2 shows the sequence of SEM micrographs of MA A 300 powders as a function of milling time. For this rotor speed, powder morphological changes occur following the usual evolution [32]; after $1 \mathrm{~h}$ of milling, the powder particles have a flake shape (Figure 2(a)); after $2 \mathrm{~h}$, they begin to weld to each other (Figure 2(b)); and after $3 \mathrm{~h}$, they tend toward an elongated multilayer structure (Figure 2(c)), which is revealed when sections of powders are studied. With increasing milling time, it was found that the elongated multilayer particles evolve to equiaxed particles, markedly decreasing their size (Figure 2(d)).

In contrast, this morphological evolution is faster for samples obtained by milling at $500 \mathrm{rpm}$. As shown in Figure 3, the particles have a flake shape after $1 \mathrm{~h}$ of milling (Figure 3(a)) and acquire an equiaxial morphology after only $2 \mathrm{~h}$ (Figure 3(b)). By increasing the milling time, the particle size is further reduced, while its geometry tends to be more rounded (Figures 3(c) and 3(d)). It can be observed that the powder tends to agglomerate, causing the aforementioned lack of symmetry of the granulometric curves of powders milled for $3 \mathrm{~h}$ and $5 \mathrm{~h}$ (MA A 500-3 and MA A 500-5).

3.3. Compressibility Test. Due to the small size of the asmilled powder particles, it was not possible to measure their microhardness. Nevertheless, a compressibility test (measuring the relative green density versus the applied compaction pressure) is an indirect method for determining the inherent hardness of powder particles [19]. This curve is very useful for determining, during the powder consolidation process, the adequate compaction pressure, that is, the desired green density. Compressibility curves of the milled powders are shown in Figure 4. Curves for the AR Al and vacuum-milled 

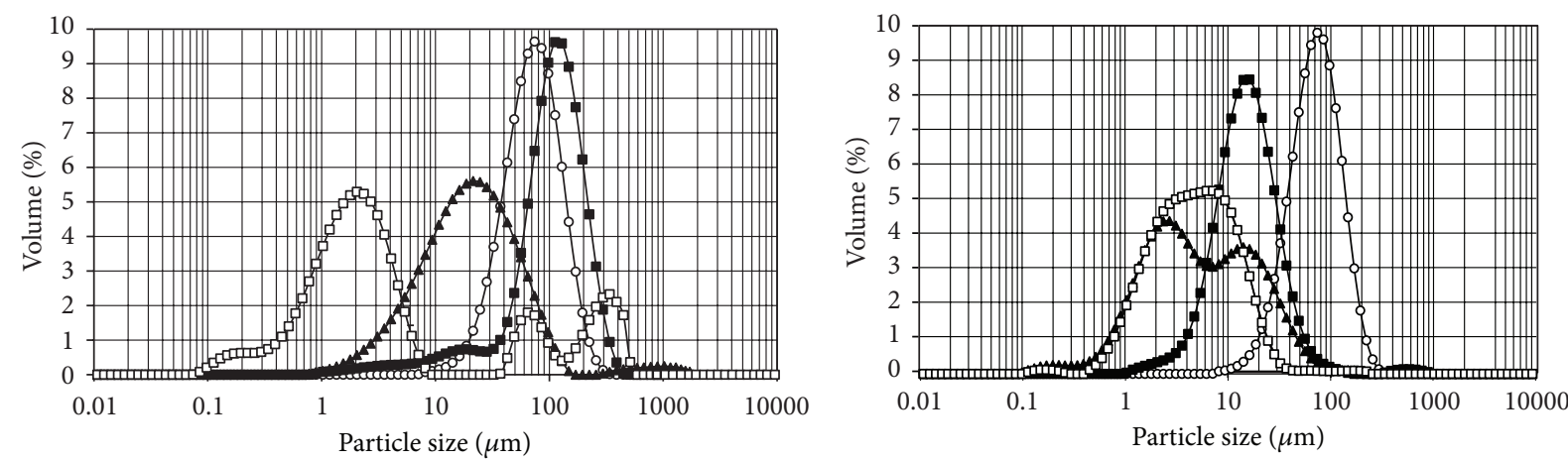

$$
\begin{array}{ll}
\multimap \text { AR Al } & \rightarrow \text { MA A 300-3 } \\
\rightarrow \text { MA A 300-1 } & \rightarrow \text { MA A 300-5 }
\end{array}
$$

(a)

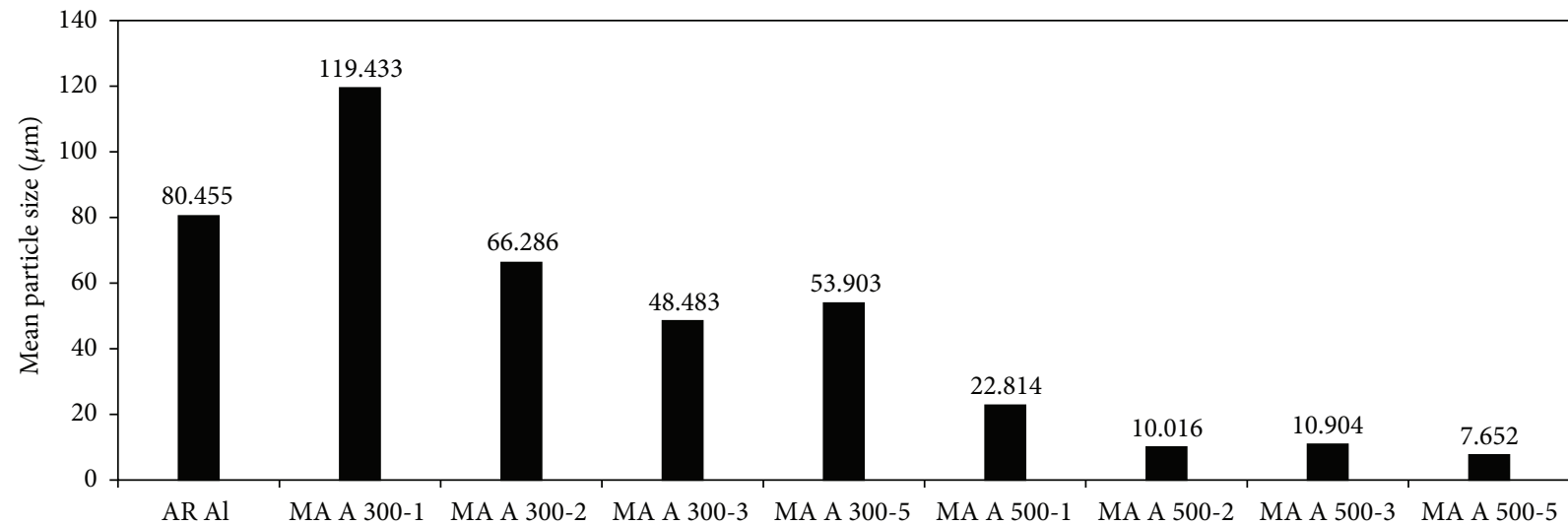

(c)

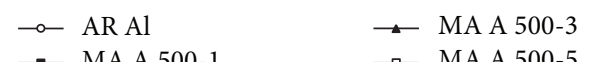

(b)

FIGURE 1: Granulometric curve of $\mathrm{AR} \mathrm{Al}$ and powders milled in $\mathrm{NH}_{3}$ flow at (a) $300 \mathrm{rpm}$ and (b) $500 \mathrm{rpm}$ for 1, 3, and $5 \mathrm{~h}$ and (c) mean particle size $(\mathrm{D} 4,3)$ of these powders.
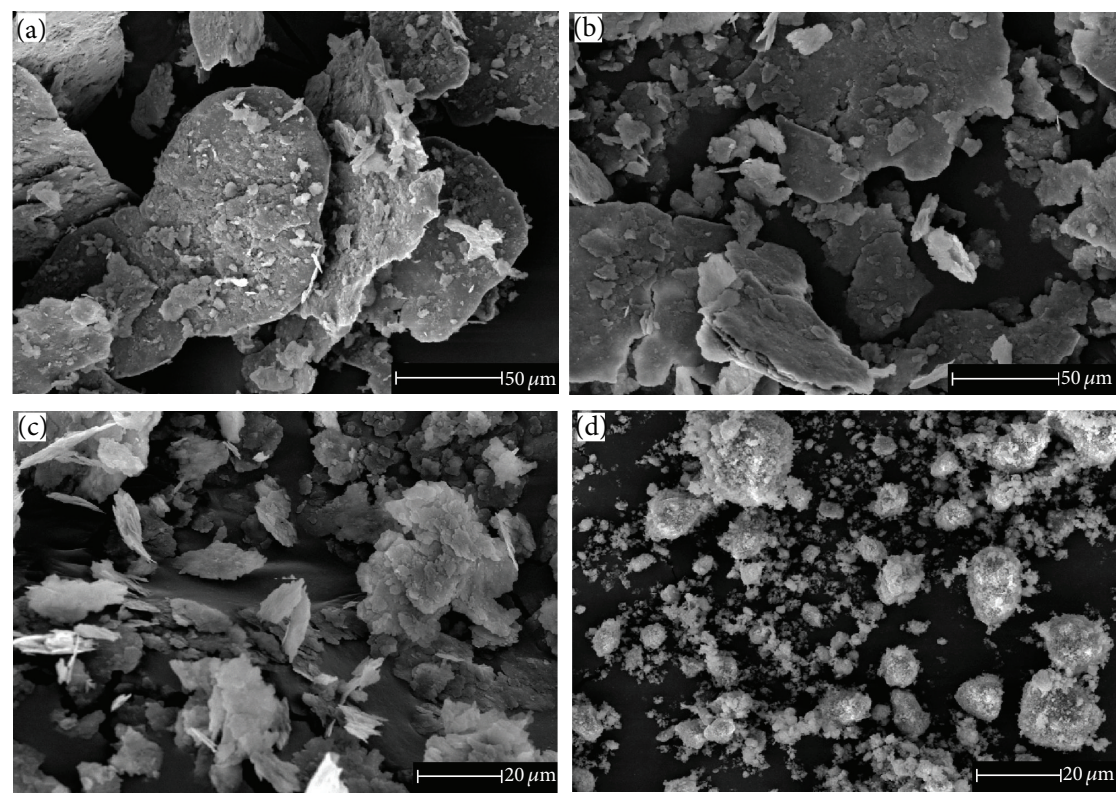

FIGURE 2: Morphological evolution of the milled powder in ammonia flow at $300 \mathrm{rpm}$ for (a) $1 \mathrm{~h}$, (b) $2 \mathrm{~h}$, (c) $3 \mathrm{~h}$, and (d) $5 \mathrm{~h}$. Note the different magnification used. 

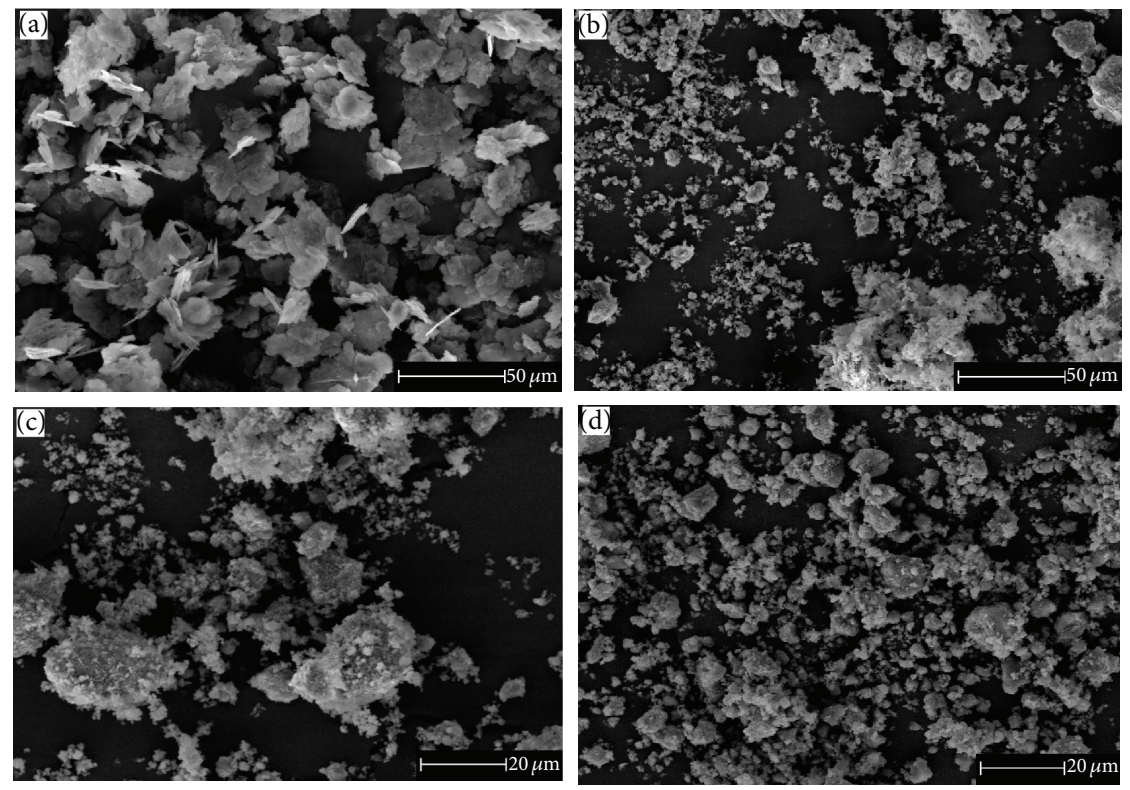

Figure 3: Morphologic evolution of powder milled in $\mathrm{NH}_{3}$ flow at $500 \mathrm{rpm}$ for (a) $1 \mathrm{~h}$, (b) $2 \mathrm{~h}$, (c) $3 \mathrm{~h}$, and (d) $5 \mathrm{~h}$. Note the different magnification used.

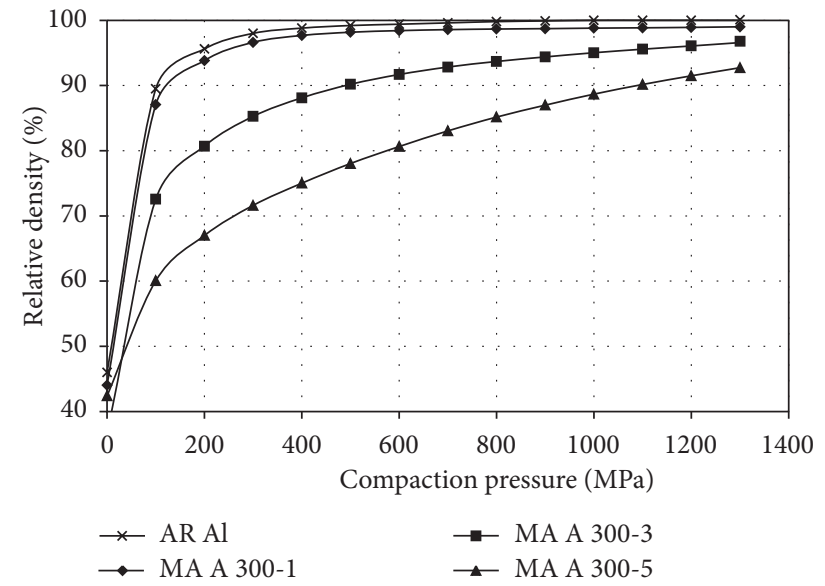

(a)

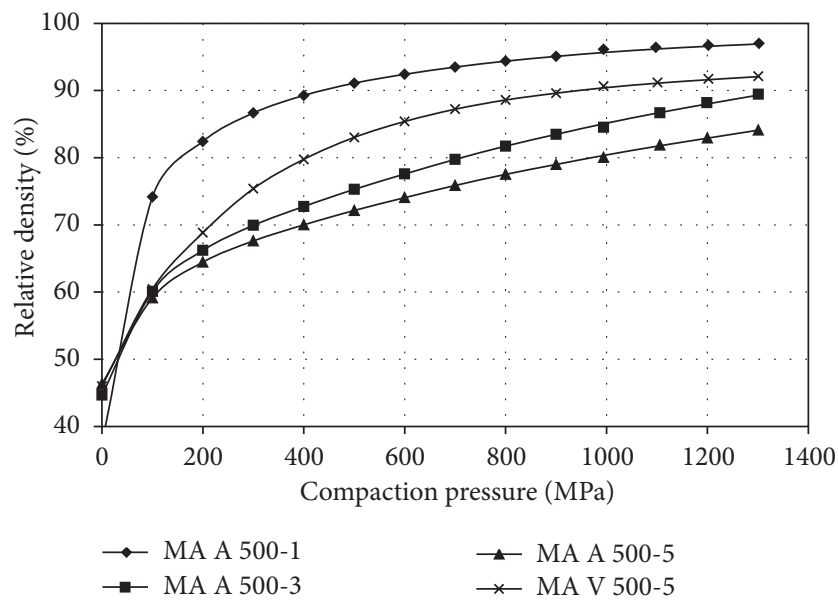

(b)

FIGURE 4: Compressibility curves of (a) AR Al and powders milled in ammonia at $300 \mathrm{rpm}$ for 1, 3, and $5 \mathrm{~h}$ and (b) powders milled at $500 \mathrm{rpm}$ in vacuum for $5 \mathrm{~h}$ and in ammonia for 1,3 , and $5 \mathrm{~h}$.

powder at $500 \mathrm{rpm}$ for $5 \mathrm{~h}$ (MA V 500-5) are also included for comparison.

The powder milled in ammonia at $300 \mathrm{rpm}$ for $1 \mathrm{~h}$ (MA A 300-1) and pressed at $500 \mathrm{MPa}$ has a relative density higher than $98 \%$ (Figure 4(a)), whereas the relative density of powder milled under the same conditions but for $5 \mathrm{~h}$ (MA A $300-5)$ is slightly higher than $78 \%$. In contrast, the AR Al powder reaches a relative density close to $100 \%$ for the same compaction pressure. This shows that, even when using a rotor speed of only $300 \mathrm{rpm}$, the strain hardening effect is quite fast with respect to milling time.
At a pressure of $500 \mathrm{MPa}$, the powders milled at $500 \mathrm{rpm}$ for 1 and $5 \mathrm{~h}$ (MA A 500-1 and MA A 500-5) reach relative densities above 90 and 70\%, respectively (Figure 4(b)). These values are slightly lower in comparison with the powders milled at $300 \mathrm{rpm}$, because, as expected, the hardening effect increases with rotor speed. However, this increase is not only due to the milling energy. In ammonia flow milling, solid solution hardening has an additional effect on the strain hardening. This assertion can be verified by comparing (Figure 4(b)) the compressibility curves of MA A 500-5 and powder milled in vacuum at the same rotor speed for the same 


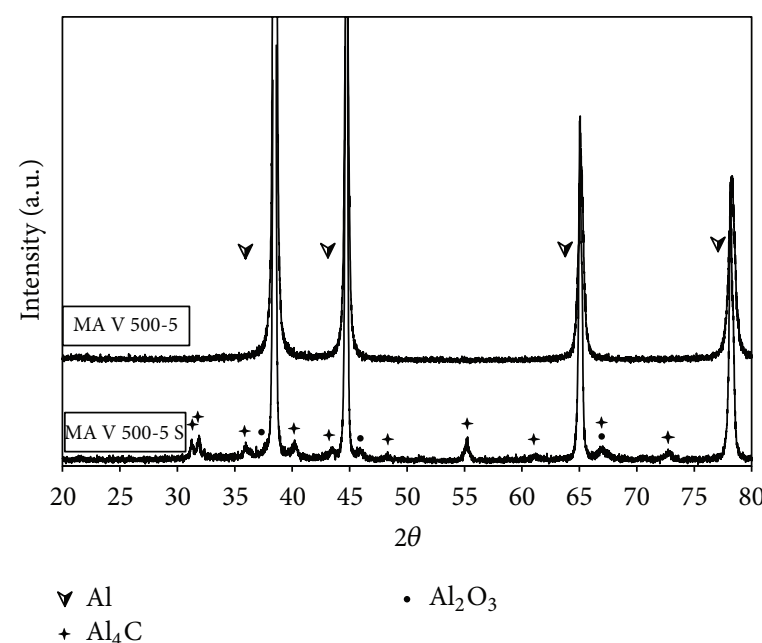

(a)

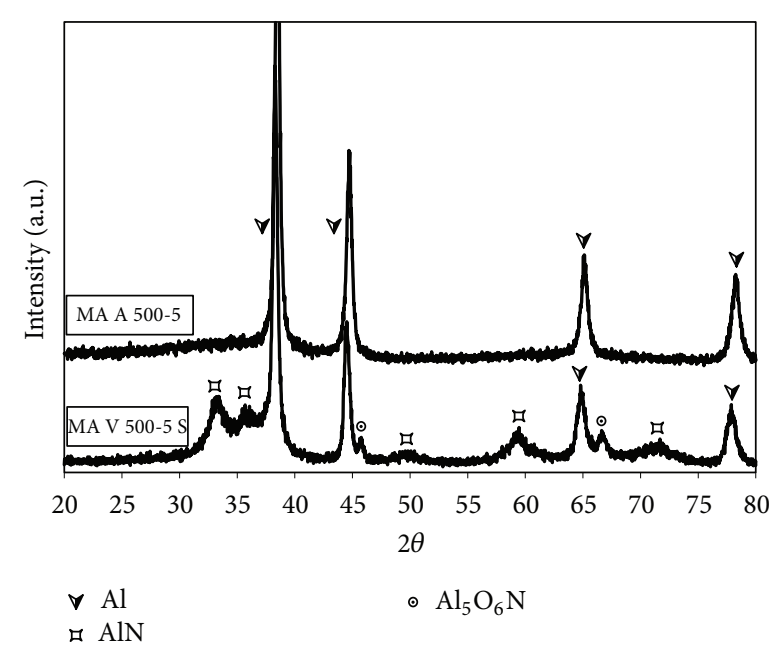

(b)

FIgURE 5: X-ray diffraction of as-milled and as-sintered $\mathrm{Al}$ powders milled for $5 \mathrm{~h}$ (a) in vacuum and (b) in ammonia gas flow.

TABLE 1: Phases present vol.\% in sintered Al powders milled in an ammonia gas flow at $500 \mathrm{rpm}$ for 1, 3, and $5 \mathrm{~h}$ (MA A 500-1 S, MA A 500-3 $S$, and MA A 500-5 S).

\begin{tabular}{lccc}
\hline Phase & & Material & \\
& MA A 500-1 S & MA A 500-3 S & MA A 500-5 S \\
\hline Aluminium (Al) & 78.45 & 46.41 & 28.87 \\
Aluminium nitride $(\mathrm{AlN})$ & 6.22 & 20.25 & 49.58 \\
Aluminium oxynitride $\left(\mathrm{Al}_{5} \mathrm{O}_{6} \mathrm{~N}\right)$ & 15.33 & 33.33 & 21.55 \\
\hline
\end{tabular}

duration (MA V 500-5). Logically, the friction force caused by interlock behaviour between irregular-shape particles could increase the hardening effect.

3.4. Microstructure. The powders milled in vacuum at $500 \mathrm{rpm}$ for $5 \mathrm{~h}$ before and after sintering (MA V 500-5 and MA V 500-5 S, resp.) were analysed by XRD to determine and quantify the phases formed (Figure 5(a)). The XRD patterns of the as-milled powders show only $\mathrm{Al}$ peaks. In contrast, in the sintered compact pattern, the presence of aluminium carbide $\left(\mathrm{Al}_{4} \mathrm{C}_{3}\right)$ and small oxide $\left(\delta-\mathrm{Al}_{2} \mathrm{O}_{3}\right)$ peaks is detected. The carbides form come from the etilen bisstearamide wax $\left(\mathrm{H}_{35} \mathrm{C}_{17} \mathrm{CONHC}_{2} \mathrm{H}_{4} \mathrm{NHCOC}_{17} \mathrm{H}_{35}\right)$ used as process controlling agent during milling, whereas the oxides mainly come from the powder particle surface.

The XRD patterns were fitted via Rietveld refinement [33], and the methods of Williamson-Hall [34] and Langford [35] were applied to calculate the crystallite size and to quantify the phases formed. These methods gave an as-milled Al crystallite size of $38 \pm 1 \mathrm{~nm}$, whereas after sintering, the crystallite size increased to $700 \pm 9 \mathrm{~nm}$. This grain growth during heating is exclusively controlled by the pinning effect of $\mathrm{Al}_{4} \mathrm{C}_{3}$ and $\mathrm{Al}_{2} \mathrm{O}_{3}$, which were present at 8.98 and 0.61 vol. $\%$, respectively.

Similar to the vacuum-milled powders, only $\mathrm{Al}$ peaks were observed in the XRD pattern (Figure 5(b)) of the powders milled, also for $5 \mathrm{~h}$, in an ammonia flow (MA A 500-5), with a crystallite size of $16 \pm 0.5 \mathrm{~nm}$. However, the situation is very different after sintering; nitrogen, in solid solution after milling, creates nanocrystalline aluminium nitride (AlN) and aluminium oxynitride $\left(\mathrm{Al}_{5} \mathrm{O}_{6} \mathrm{~N}\right)(12 \pm 0.5$ and $4 \pm$ $0.2 \mathrm{~nm}$, resp., also calculated by XRD) during powder heating (Figure 5(b)). Thus, the proposed mechanosynthesis process can produce $\mathrm{NH}_{3}$ dissociation at room temperature, whereas under normal conditions (without milling), this occurrence only happens at temperatures of approximately $550^{\circ} \mathrm{C}$. This could be an advantage over other methods for preparing $\mathrm{Al} / \mathrm{AlN}$ composites, which usually include complicated steps or are performed at very low or high temperatures [3639]. As expected, the quantity of aluminium nitride and oxynitride depends on the milling time, as shown in the quantification results of Table 1 . It is notable that, after $3 \mathrm{~h}$ and $5 \mathrm{~h}$ of milling at $500 \mathrm{rpm}, 20.25$ and $49.58 \mathrm{vol} \%$ of AlN were, respectively, obtained, showing that the formation of AlN with this method is very effective, even for short milling times.

Even more interesting is the effect that these nanocrystalline dispersoids have on $\mathrm{Al}$ grain growth. After sintering, the $\mathrm{Al}$ crystallite size of powders milled $5 \mathrm{~h}$ in vacuum increased to $700 \pm 9 \mathrm{~nm}$, as measured on the XRD pattern, while it increased only to $45 \pm 1 \mathrm{~nm}$ for powders milled in an ammonia gas flow for the same duration.

In order to check these sizes, consolidated compacts have been studied by TEM. Figure 6(a) shows a bright field image of a sintered compact prepared from $5 \mathrm{~h}$ vacuum-milled powders. Results by image analysis on micrographs of these 


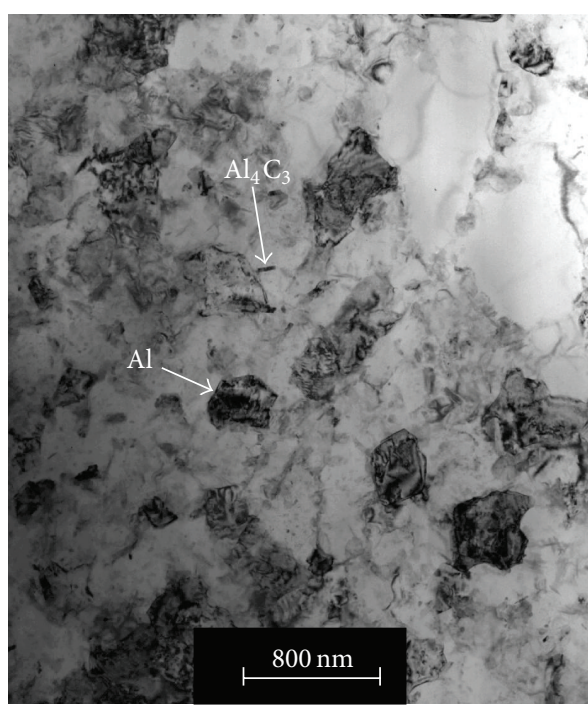

(a)

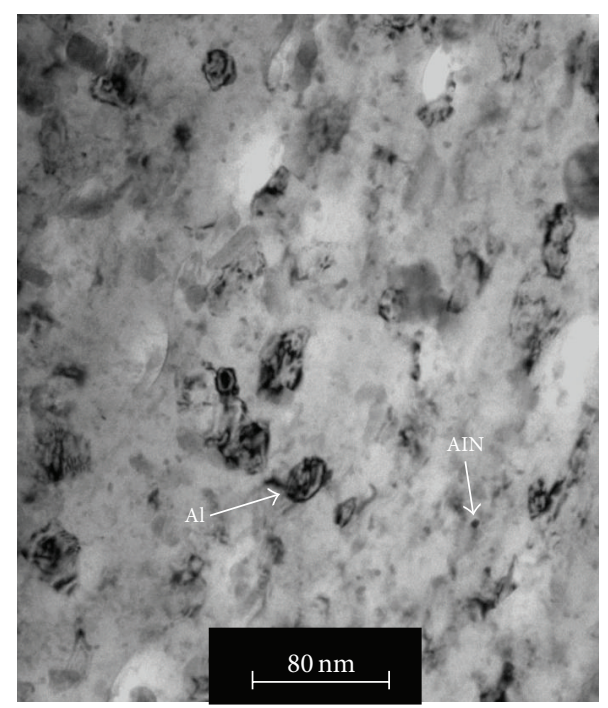

(b)

FIGURE 6: Bright-field TEM images of sintered compacts showing different phases formed in (a) MA V 500-5 S and (b) MA A 500-5 S.

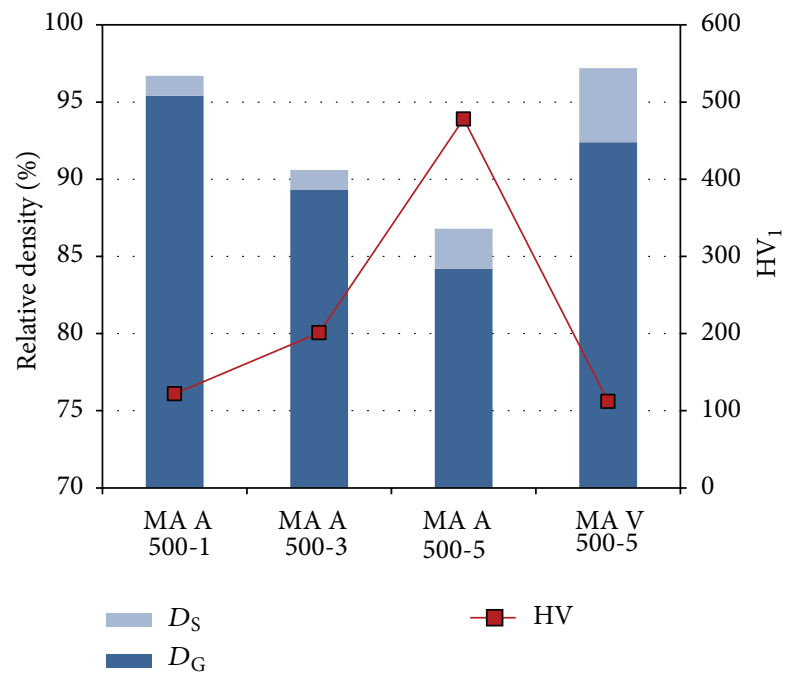

FIGURE 7: Green $\left(D_{G}\right)$ and sintered $\left(D_{S}\right)$ relative density and Vickers hardness of sintered compacts from powders milled at $500 \mathrm{rpm}$ in vacuum for $5 \mathrm{~h}$ and in an ammonia flow for 1,3 , and $5 \mathrm{~h}$.

specimens give an $\mathrm{Al}$ mean grain size of $709 \pm 20 \mathrm{~nm}$, resulting in 15 times that of $\mathrm{Al}$ grains in specimens prepared from powder milled under ammonia flow for $5 \mathrm{~h}$ (Figure 6(b)), which resulted to be only of $43 \pm 9 \mathrm{~nm}$ as obtained by image analysis from TEM images.

The aforementioned remarkable amount of dispersoids, together with the small $\mathrm{Al}$ grain size, surely increases the hardness of compacts processed from powders milled in an ammonia flow. However, this expected hardness could be reduced due to the difficulty in consolidating such hard powders.

Figure 7 shows the green $\left(D_{\mathrm{G}}\right)$ and sintered $\left(D_{\mathrm{S}}\right)$ relative densities of compacts prepared from powders milled in an ammonia flow at $500 \mathrm{rpm}$. The values of MA V 500-5 are also included for comparison. The low hardness of the MA A 500-1 powders makes it possible to reach high green densities (95.4\%); however, the flake shape and relatively large size of the particles make the sintering process difficult, increasing the density by only $1.3 \%$. An increase in the milling time to 3 or $5 \mathrm{~h}$ makes the powders harden, avoiding high green densities after the pressing stage. Despite the high specific area of both powders, due to their small size, their low green density seems to be the reason, together with the lower sinterability of the refractory phases (now in a higher amount), that the sinterability level of these samples is constrained (Figure 7). Improvements in the relative densities of the final products are currently under study in the authors' laboratory, using additives such as copper to promote liquid phase sintering.

The nanosized $\mathrm{Al}$ grains and the presence of hard phases dispersed in the compacts prepared from ammonia-milled powders make their hardness be, despite their relatively elevated porosities, higher than those achieved in compacts prepared from vacuum-milled powders (Figure 7). It is remarkable that hardness of $478 \mathrm{HV}_{1}$ was achieved in sintered compacts of powders milled for $5 \mathrm{~h}$ in $\mathrm{NH}_{3}$.

\section{Conclusions}

Aluminium powder was attrition-milled in an ammonia flow of $1 \mathrm{~cm}^{3} / \mathrm{s}$ for 1 to $5 \mathrm{~h}$, with rotor speeds of 300 and $500 \mathrm{rpm}$. The following conclusions are drawn.

(1) A simple method at room temperature has been developed to produce bulk aluminium-based nanocomposites reinforced with in situ generated aluminium nitride and oxynitride nanodispersoids.

(2) During milling, the ammonia is decomposed, and high quantities of nitrogen are incorporated into the 
Al powder, hardening it by solid solution. Thus, it is possible to obtain small and hard equiaxial particles after only $2 \mathrm{~h}$ of milling.

(3) The milled powders, both in vacuum or in $\mathrm{NH}_{3}$ gas flow, only show the presence of aluminium with a crystallite size of approximately $38 \pm 1$ and $16 \pm 0.5 \mathrm{~nm}$, respectively. After heating, aluminium nitride (AlN) and oxynitride $\left(\mathrm{Al}_{5} \mathrm{O}_{6} \mathrm{~N}\right)$ are formed in the ammoniaflow-milled powders, whereas in the vacuum-milled powders, only aluminium oxide $\left(\mathrm{Al}_{2} \mathrm{O}_{3}\right)$ and carbide $\left(\mathrm{Al}_{4} \mathrm{C}_{3}\right)$ appear.

(4) The ammonia-flow-milled powders have a high quantity of AlN (up to 49.58 vol.\%) and $\mathrm{Al}_{5} \mathrm{O}_{6} \mathrm{~N}$ nanometric dispersoids, with crystallite sizes below $12 \pm$ $0.5 \mathrm{~nm}$. Thus, these phases highly restrict aluminium grain growth during sintering, keeping it below $45 \pm$ $1 \mathrm{~nm}$ (MA A 500-5 S).

(5) The final compacts produced with these ammoniaflow-milled powders exhibit high hardness (up to $478 \mathrm{HV}_{1}$ ), despite their low relative density values.

\section{Conflict of Interests}

The authors declare that there is no conflict of interests regarding the publication of this paper.

\section{Acknowledgments}

Financial support of the Ministerio de Ciencia e Innovación, Spain, through the research Projects DPI2012-37948-C02-01 and DPI2009-08291 is gratefully acknowledged. The authors also wish to thank the technicians J. Pinto, M. Madrid and M. Sánchez (University of Seville, Spain) for the experimental assistance.

\section{References}

[1] C. Joachim, “To be nano or not to be nano?" Nature Materials, vol. 4, pp. 107-109, 2005.

[2] T. G. Langdon, "The impact of bulk nanostructured materials in modern research," Reviews on advanced materials science, vol. 25, no. 1, pp. 11-15, 2010.

[3] R. Z. Valiev, M. J. Zehetbauer, Y. Estrin et al., "The innovation potential of bulk nanostructured materials," Advanced Engineering Materials, vol. 9, no. 7, pp. 527-533, 2007.

[4] H. Gleiter, "Nanocrystalline materials," Progress in Materials Science, vol. 33, no. 4, pp. 223-315, 1989.

[5] R. Valiev, "Nanostructuring of metals by severe plastic deformation for advanced properties," Nature Materials, vol. 3, pp. 511-516, 2004.

[6] W. H. Hunt Jr., "Nanomaterials: nomenclature, novelty, and necessity," JOM, vol. 56, no. 10, pp. 13-18, 2004.

[7] H. Gleiter, "Nanostructured materials: state of the art and perspectives," Nanostructured Materials, vol. 6, no. 1-4, pp. 314, 1995.

[8] A. P. Newbery, B. Ahn, T. D. Topping, P. S. Pao, S. R. Nutt, and E. J. Lavernia, "Large UFG Al alloy plates from cryomilling,"
Journal of Materials Processing Technology, vol. 203, no. 1-3, pp. 37-45, 2008.

[9] A. S. Khan, B. Farrokh, and L. Takacs, "Effect of grain refinement on mechanical properties of ball-milled bulk aluminum," Materials Science and Engineering A, vol. 489, no. 1-2, pp. 77-84, 2008.

[10] C. C. Koch, "Structural nanocrystalline materials: an overview," Journal of Materials Science, vol. 42, no. 5, pp. 1403-1414, 2007.

[11] C. Suryanarayana, "The structure and properties of nanocrystalline materials: issues and concerns," JOM, vol. 54, no. 9, pp. 24-27, 2002.

[12] D. L. Zhang, "Processing of advanced materials using highenergy mechanical milling," Progress in Materials Science, vol. 49, no. 3-4, pp. 537-560, 2004.

[13] Z. R. Hesabi, S. Kamrani, A. Simchi, and S. M. S. Reihani, "Effect of nanoscaled reinforcement particles on the structural evolution of aluminium powder during mechanical milling," Powder Metallurgy, vol. 52, no. 2, pp. 151-157, 2009.

[14] J. Ye, B. Q. Han, Z. Lee, B. Ahn, S. R. Nutt, and J. M. Schoenung, "A tri-modal aluminum based composite with super-high strength," Scripta Materialia, vol. 53, no. 5, pp. 481486, 2005.

[15] H. Mohseni, S. Keirs, S. L. I. Chan, and M. Ferry, "High temperature stability of fine grained $7075 \mathrm{Al}$ alloy containing nanosized SiC particles," Materials Science and Technology, vol. 26, no. 5, pp. 597-603, 2010.

[16] Z. Z. Chen and K. Tokaji, "Effects of particle size on fatigue crack initiation and small crack growth in $\mathrm{SiC}$ particulate-reinforced aluminium alloy composites ," Materials Letters, vol. 58, no. 1718, pp. 2314-2321, 2004.

[17] C. F. Chen, P. W. Kao, L. Chang, and N. J. Ho, "Mechanical properties of nanometric $\mathrm{Al}_{2} \mathrm{O}_{3}$ particulate-reinforced $\mathrm{Al}^{-\mathrm{Al}_{11}} \mathrm{Ce}_{3}$ composites produced by friction stir processing," Materials Transactions, vol. 51, pp. 933-938, 2010.

[18] B. Prabhu, C. Suryanarayana, L. An, and R. Vaidyanathan, "Synthesis and characterization of high volume fraction Al$\mathrm{Al}_{2} \mathrm{O}_{3}$ nanocomposite powders by high-energy milling," Materials Science and Engineering A, vol. 425, no. 1-2, pp. 192-200, 2006.

[19] J. Cintas, F. G. Cuevas, J. M. Montes, and E. J. Herrera, "High-strength PM aluminium by milling in ammonia gas and sintering," Scripta Materialia, vol. 53, no. 10, pp. 1165-1170, 2005.

[20] J. Cintas, F. G. Cuevas, J. M. Montes, and E. J. Herrera, "Microstructural control of sintered mechanically alloyed Al$1 \%$ Ni material," Scripta Materialia, vol. 52, no. 5, pp. 341-345, 2005.

[21] F. G. Cuevas, J. Cintas, J. M. Montes, and J. M. Gallardo, "AlTi powder produced through mechanical alloying for different times," Journal of Materials Science, vol. 41, no. 24, pp. 83398346, 2006.

[22] J. Cintas, F. G. Cuevas, J. M. Montes, E. S. Caballero, and E. J. Herrera, "Strengthening of ultrafine PM aluminium using nano-sized oxycarbonitride dispersoids," Materials Science and Engineering A, vol. 528, no. 28, pp. 8286-8291, 2011.

[23] J. Cintas, J. M. Montes, F. G. Cuevas, and E. J. Herrera, "Heat-resistant bulk nanostructured P/M aluminium," Journal of Alloys and Compounds, vol. 458, no. 1-2, pp. 282-285, 2008.

[24] J. Cintas, J. A. Rodríguez, J. M. Gallardo, and E. J. Herrera, “The impact of bulk nanostructured materials in modern research," Revista de Metalurgia, vol. 37, no. 2, pp. 370-375, 2001. 
[25] P. G. Zhang, K. Y. Wang, and S. M. Guo, "Large-scale synthesis of AlN nanofibers by direct nitridation of aluminum," Ceramics International, vol. 36, no. 7, pp. 2209-2213, 2010.

[26] Z. Liu, B. Wu, and M. Gu, "An investigation of micro-galvanic corrosion in $\mathrm{Al} / \mathrm{AlN}_{p}$ composites," Materials Chemistry and Physics, vol. 102, no. 1, pp. 43-46, 2007.

[27] H. Yu, H. Chen, R. Ma, and G. Min, "Fabrication of AlN-TiC/Al composites by gas injection processing," Rare Metals, vol. 25, no. 6, pp. 659-664, 2006.

[28] S. W. Lai and D. D. L. Chung, "Fabrication of particulate aluminium-matrix composites by liquid metal infiltration," Journal of Materials Science, vol. 29, no. 12, pp. 3128-3150, 1994.

[29] A. Inoue, K. Nosaki, B. G. Kim, T. Yamaguchi, and T. Masumoto, "Mechanical strength of ultra-fine Al-AlN composites produced by a combined method of plasma-alloy reaction, spray deposition and hot pressing," Journal of Materials Science, vol. 28, no. 16, pp. 4398-4404, 1993.

[30] D. F. Lii, J. L. Huang, and S. T. Chang, "The mechanical properties of AlN/Al composites manufactured by squeeze casting," Journal of the European Ceramic Society, vol. 22, no. 2, pp. 253-261, 2002.

[31] H. Abdoli, E. Salahi, H. Farnoush, and K. Pourazrang, "Evolutions during synthesis of Al-AlN-nanostructured composite powder by mechanical alloying," Journal of Alloys and Compounds, vol. 461, no. 1-2, pp. 166-172, 2008.

[32] J. Cintas, J. M. Montes, F. G. Cuevas, and J. M. Gallardo, "Influence of PCA content on mechanical properties of sintered MA aluminium," Materials Science Forum, vol. 514-516, no. 2, pp. 1279-1283, 2006.

[33] R. A. Young, Ed., The Rietveld Method, Oxford University Press, New York, NY, USA, 2000.

[34] G. K. Williamson and W. H. Hall, "An abnormal after-effect in metals," Acta Metallurgica, vol. 1, no. 1, pp. 2-31, 1953.

[35] J. I. Langford, "A rapid method for analysing the breadths of diffraction and spectral lines using the Voigt function ", Journal of Applied Crystallography, vol. 11, pp. 10-14, 1978.

[36] Y. Q. Liu, H. T. Cong, W. Wang, C. H. Sun, and H. M. Cheng, "AlN nanoparticle-reinforced nanocrystalline Al matrix composites: fabrication and mechanical properties," Materials Science and Engineering A, vol. 505, pp. 151-156, 2009.

[37] Y. Li, Y. H. Zhao, V. Ortalan et al., "Investigation of aluminumbased nanocomposites with ultra-high strength," Materials Science and Engineering A, vol. 527, no. 1-2, pp. 305-316, 2009.

[38] K. B. Lee, H. S. Sim, and H. Kwon, "Fabrication of Al/AlN composites by in situ reaction," Journal of Materials Science, vol. 41, no. 19, pp. 6347-6352, 2006.

[39] J. Shengli, L. Yawei, L. Jing et al., "Microstructure and phase composition of AlN/Al composite fabricated by directed melt nitridation," Key Engineering Materials, vol. 368-372, no. 2, pp. 977-979, 2008. 

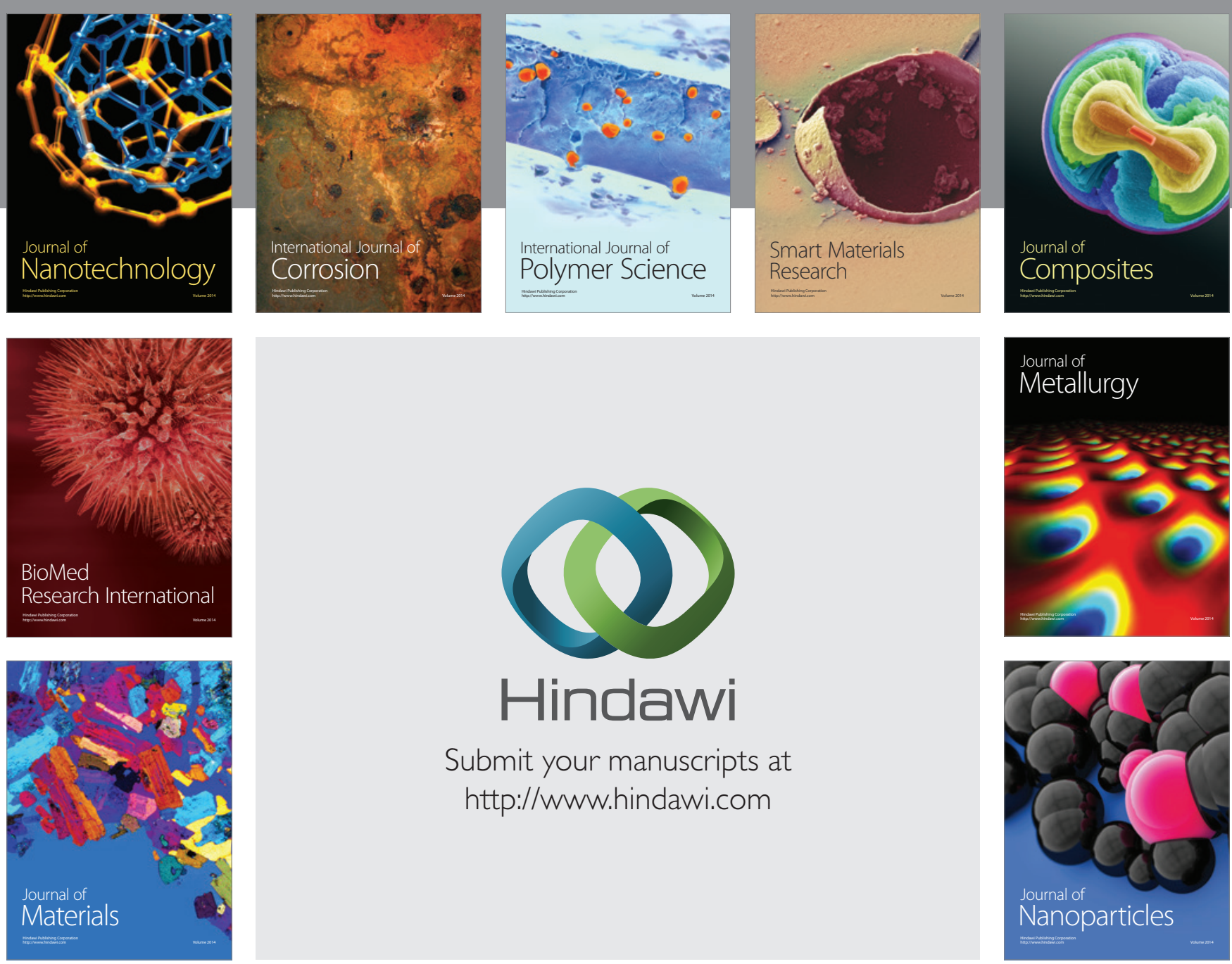

Submit your manuscripts at http://www.hindawi.com
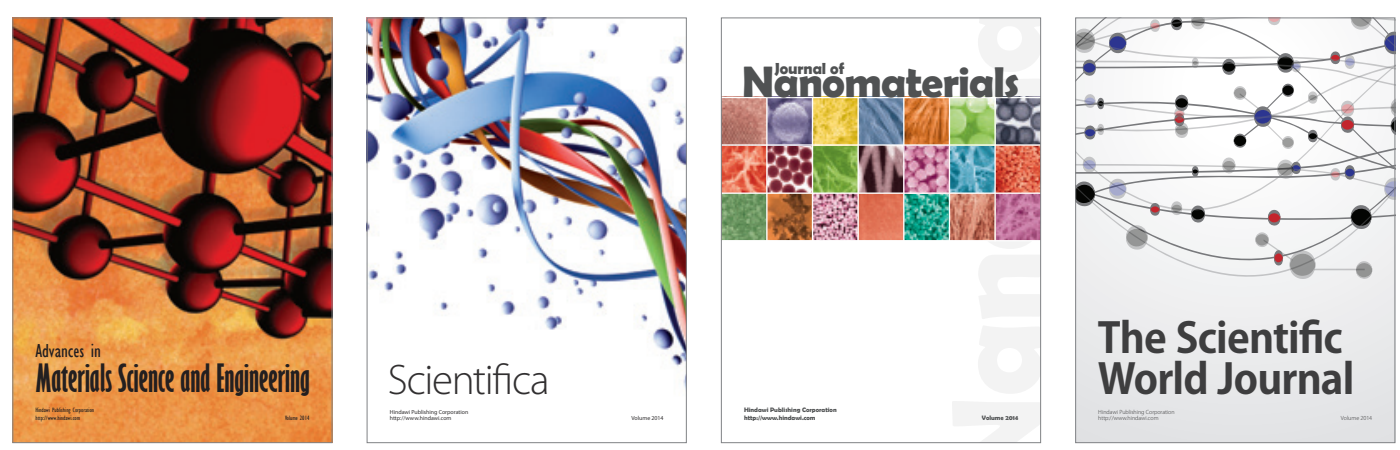

\section{The Scientific World Journal}
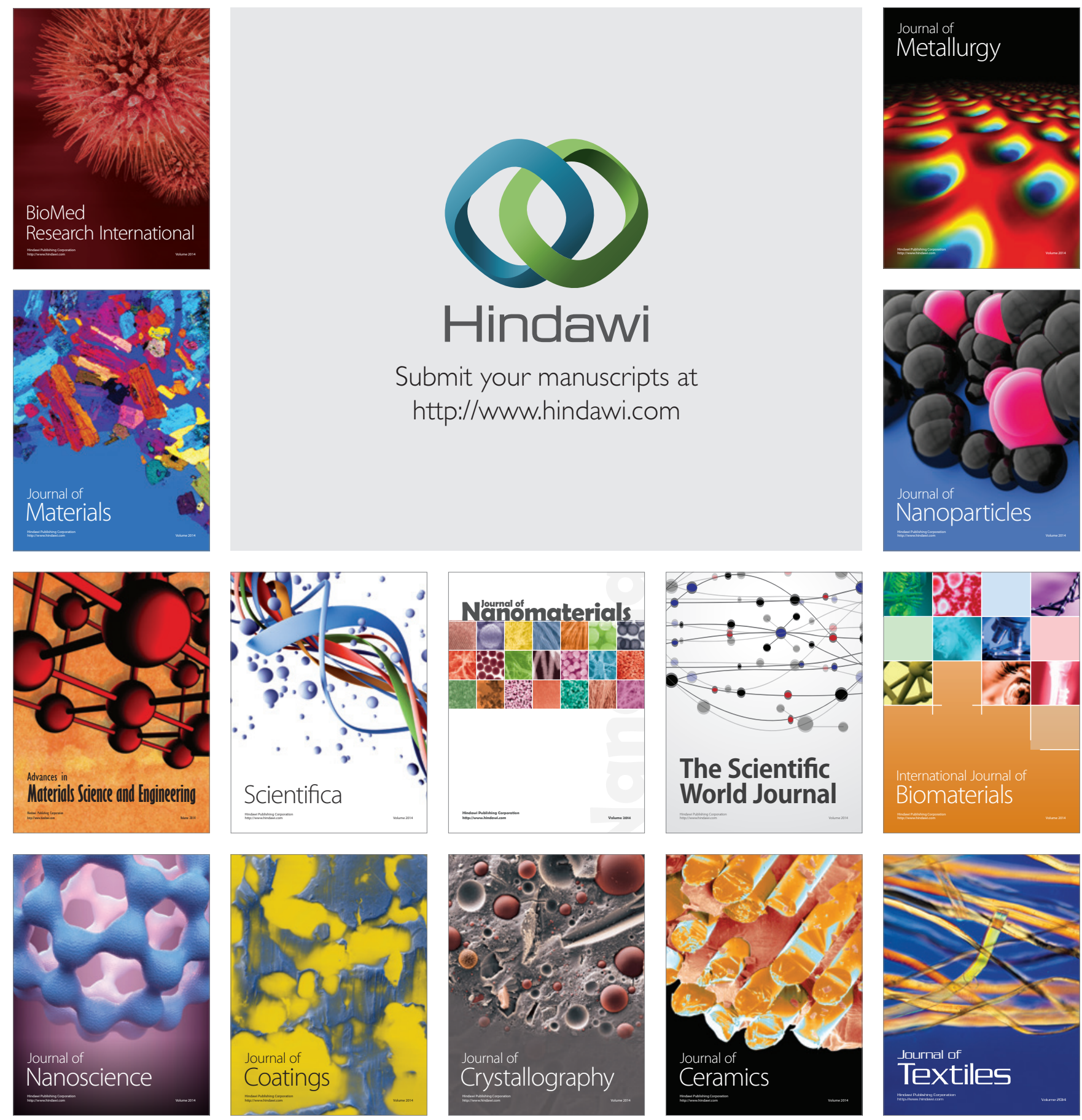